\title{
Empirical Research: Career Burnout of Public Hospital Staff in China
}

\author{
Jianglin Ke \\ School of Government \\ Beijing Normal University \\ Beijing, China \\ Chen Chen \\ School of Government \\ Beijing Normal University \\ Beijing, China
}

\author{
Xiaocen Yan \\ School of Government \\ Beijing Normal University \\ Beijing, China \\ Shanshan Kuang \\ School of Government \\ Beijing Normal University \\ Beijing, China
}

\begin{abstract}
The public hospital is the main medical institutions in China, and the medical staff is the key part of the hospital, so effectively mobilizing the enthusiasm of the medical staff has a major impact on enhancing the dominant status of the public hospitals. In recent years, with the gradual progress of China's medical reform, the demand for doctors and nurses is gradually increasing. However, the reality is becoming more and more severe. Therefore, it is of vital importance to explore and develop the theory of career burnout of the hospital staff in China. Based on the hierarchical regression analysis of 327 questionnaires, the study finds that career burnout has a positive effect on the turnover intension and a significant negative effect on the organizational commitment. Public hospitals should decrease the career burnout of the hospital staff so as to retain employees and hence their organizational commitment.
\end{abstract} strategy

Keywords-medical staff, career burnout, improvement

\section{INTRODUCTION}

Career burnout refers to the individual physical and mental fatigue produced by work stress. The concept was first proposed in 1974 by the Freudenberger. He thought career burnout is most likely to occur in service industry. Later many scholars summarized the definition of career burnout from different angles, including dynamic explanation and static explanation.

The medical staff in public hospitals is a high incidence of career burnout group owing to their current occupational characteristics. Firstly, due to individual differences and the complex severity of the patient's condition, the medical results are always unpredictable. Therefore the medical staff has a higher practical risk of the practice. Meanwhile, the daily medical work requires that staff respond to problems quickly and accurately, so they are always under a lot of mental pressure.

Secondly, the tense physician-patient relationship and the frequent medical disputes has become a common problem in

Supported by " the Fundamental Research Funds for the Central Universities medical service. On the one hand, some patients and their families don't have a good understanding of medical activities risk. They blame all the adverse effects of treatment on the doctors. On the other hand, some of the medical staff is in violation of relevant rules. They ask for patient's money and selling high-priced drugs. Such behaviors also deepen the distrust between doctors and patients.

Various factors lead to following results: medical staff's low job enthusiasm; serious decrease in job satisfaction; higher career burnout.

Most academic researches of public hospital staff career burnout focused on its multi-factors and interventions. However, during the critical period of hospital management transformation and the grass-roots medical reform, previous studies are not fully applicable. So we introduce organizational commitment and turnover intention two new factors to analyze the impact of career burnout. And accordingly we can further research the harm of career burnout, and propose some advice to compensate for the lack in the research field in this particular period.

\section{LITERATURE AND HYPOTHESIS}

Lee et al. (1996) showed that emotional exhaustion has a significant effect on reducing occupational commitment. Maslach and Leiter (1988) found that interpersonal relationships play a buffer role between career burnout and organizational commitment in hospitals. Sethi et al. (1987) further studied the impact of career burnout on organizational commitment in continuance commitment and affective commitment. He found continuance commitment and career burnout has a significantly positive correlation. This leads to the following hypothesis:

H1: Career burnout has a negative effect on organizational commitment.

Maslach (1981) found that accounting practitioners who have career burnout are more prone to have turnover intention in comparison. Pines (1989) found if career burnout was 
sustained, it would eventually lead to turnover behavior; Lee et al. (1996) found that emotional exhaustion is mainly due to the conflict of roles and workload, and career burnout can lead to turnover intention and reduce the sense of belonging as well. This leads to the following hypothesis:

$\mathrm{H} 2$ : Career burnout has a positive effect on turnover intention.

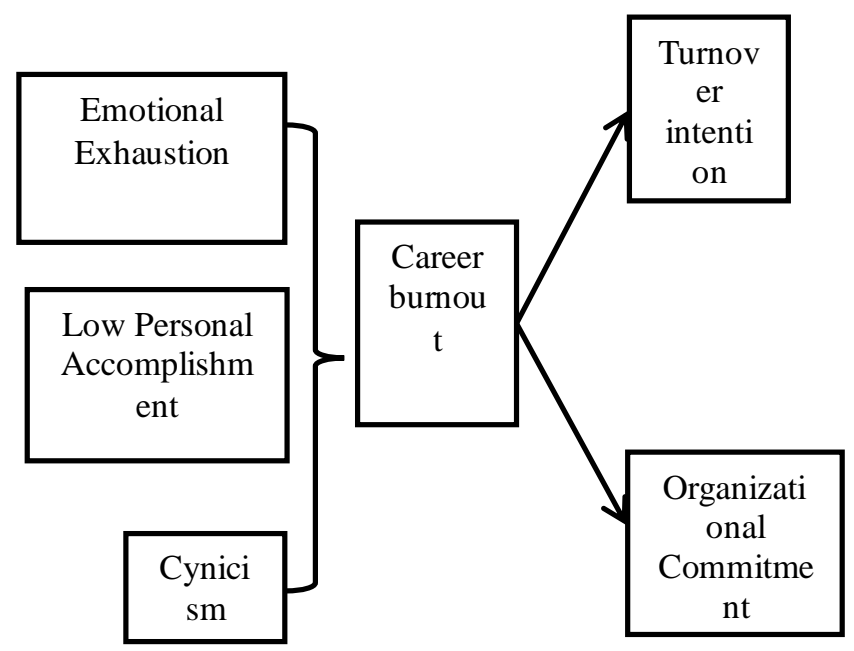

Fig. 1.

\section{METHOD}

\section{A. Sample}

We collected 327 valid questionnaires, and the data were analyzed by using the Least-Significant Difference (LSD). The respondents were public hospital medical staff.

Among them, women accounted for $63.6 \%$; the age ranged from 20 to 50; married accounted for $60.9 \%$; tertiary education accounted for $24.8 \%$; undergraduate education accounted for $44.0 \%$; master and doctoral degree accounted for $31.2 \%$.

In these medical staff, doctors accounted for $48.6 \%$; nurses accounted for $51.4 \%$; the no titled staff accounted for $10.4 \%$; the junior titled staff accounted for $35.5 \%$; the intermediate titled accounted for $41.6 \%$; the senior titled accounted for $12.5 \%$ only.

\section{B. Measuring}

For career burnout, the study adopted the MBI-GS (Maslach Burnout Inventory-General Survey) by Li Chaoping. The scale uses Likert 7 points rating scale, 0 represents "never" and 6 represents that frequency is "Every day."
For organizational commitment, we adopted scale by Ling Wenquan which was developed to research Chinese organizational commitment. This scale includes affective commitment, ideal commitment, normative commitment, opportunity commitment and economic commitment. The questionnaire was evaluated using five score, "disagree" to "extreme agree" five options were scored 1-5 points.

For turnover intention, we have 6 questions. The questionnaire adopts a single factor structure. "Never" to "often" or "very unlikely" to "very likely" were scored 1-4 points.

\section{Test of Scale}

We test reliability and reliability of scale. Cronbach's $\alpha$ value of each subscale was over 0.7 , indicating each subscale reliable.

We did CFA for all projects of three subscales. According to the principle that factor loadings should not be less than 0.5 , we tested structural validity. The results showed all projects meet the requirements. The amount of each factor loading was over 0.50 , indicating that the scale has good construct validity.

\section{Descriptive Statistics}

1) Overall Analysis: Currently the career burnout levels of medical staff in public hospitals are in the medium to high. While their organizational commitment levels are low and turnover intention level medium to high, indicating that the current public hospital staff have strong career burnout and weak stability.

2) Variance Analysis of Career Burnout: The study used the method of independent samples T-test and ANOVA analysis, analyzing the differences of career burnout in gender, age, marital status, education, jobs, job category and other demographic variables, so as to understand the current situation of public hospitals in all aspects. The results showed that career burnout and its three dimensions had no significant difference in gender, marital status, jobs, education, and job title. We designed five intervals of age, specifically,"20-30", "31-40", "41-50"," 51-60", ">60" and did ANOVA and post hoc comparisons of career burnout and its three dimensions in age. The results showed there were significant differences in the emotional exhaustion of respondents from " $41-50$ " and "20-30" and the cynicism level of respondents of 51-60 was significantly higher than that of the respondents from " $31-40$ " and "41-50". Respondents over 51 years old had a remarkably higher personal accomplishment level than those who are under 50. Overall the career burnout level of " $20-30$ " is significantly higher than that of "41-50". 
TABLE I. COMPARISON OF CAREER BURNOUT AND ITS THREE DIMENSIONS ON AGE

\begin{tabular}{|c|c|c|c|c|c|c|}
\hline & $\begin{array}{c}\text { Sources of } \\
\text { variation }\end{array}$ & $\begin{array}{c}\text { sum of squares of } \\
\text { deviation from } \\
\text { mean }\end{array}$ & df & RMSE & $\mathbf{F}$ & Sig \\
\hline \multirow[t]{3}{*}{ Emotional exhaustion } & interior - group & 7.608 & 4 & 1.902 & 1.616 & .170 \\
\hline & inter - group & 379.022 & 322 & 1.177 & & \\
\hline & sum & 386.630 & 326 & & & \\
\hline \multirow[t]{3}{*}{ Cynicism } & interior - group & 16.668 & 4 & 4.167 & $2.792 *$ & .026 \\
\hline & inter - group & 480.580 & 322 & 1.492 & & \\
\hline & sum & 497.248 & 326 & & & \\
\hline \multirow{3}{*}{$\begin{array}{l}\text { Low personal } \\
\text { accomplishment }\end{array}$} & interior - group & 12.023 & 4 & 3.006 & $2.421 *$ & .048 \\
\hline & inter - group & 399.690 & 322 & 1.241 & & \\
\hline & sum & 411.713 & 326 & & & \\
\hline \multirow[t]{3}{*}{ Career burnout } & interior - group & 1.724 & 4 & .431 & 2.331 & .056 \\
\hline & inter - group & 59.548 & 322 & .185 & & \\
\hline & sum & 61.272 & 326 & & & \\
\hline
\end{tabular}

TABLE II. POST Hoc COMPARISONS OF AGE

\begin{tabular}{|c|c|c|c|c|c|c|c|c|c|c|c|}
\hline & \multirow{2}{*}{ team } & \multirow{2}{*}{ age } & \multirow{2}{*}{ amount } & \multirow{2}{*}{ mean } & \multirow{2}{*}{ SD } & \multicolumn{5}{|c|}{ Team } & \multirow{2}{*}{ LSD } \\
\hline & & & & & & 1 & 2 & 3 & 4 & 5 & \\
\hline \multirow{5}{*}{ Emotional exhaustion } & 1 & $20-30$ & 97 & 3.13 & 1.133 & - & & $*$ & & & $1>3$ \\
\hline & 2 & $31-40$ & 126 & 3.06 & 1.094 & & - & & & & \\
\hline & 3 & $41-50$ & 76 & 2.78 & .918 & & & - & & & \\
\hline & 4 & $51-60$ & 20 & 3.30 & 1.380 & & & & - & & \\
\hline & 5 & $>60$ & 8 & 3.12 & .991 & & & & & - & \\
\hline \multirow{4}{*}{ Cynicism } & 2 & $31-40$ & 126 & 3.01 & 1.170 & & - & & $*$ & & $4>2$ \\
\hline & 3 & $41-50$ & 76 & 2.87 & 1.024 & & & - & $* *$ & & $4>3$ \\
\hline & 4 & $51-60$ & 20 & 3.75 & 1.118 & & & & - & & \\
\hline & 5 & $>60$ & 8 & 3.62 & 1.598 & & & & & - & \\
\hline \multirow{4}{*}{$\begin{array}{l}\text { Low personal } \\
\text { accomplishment }\end{array}$} & 2 & $31-40$ & 126 & 3.55 & 1.150 & & - & & $*$ & & $2>4$ \\
\hline & 3 & $41-50$ & 76 & 3.59 & .982 & & & - & $*$ & & $3>4$ \\
\hline & 4 & $51-60$ & 20 & 2.95 & 1.050 & & & & - & & \\
\hline & 5 & $>60$ & 8 & 2.75 & 1.389 & & & & & - & \\
\hline \multirow{5}{*}{ Career Burnout } & 1 & $20-30$ & 97 & 3.30 & .503 & - & & $* *$ & & & $3>1$ \\
\hline & 2 & $31-40$ & 126 & 3.21 & .426 & & - & & & & \\
\hline & 3 & $41-50$ & 76 & 3.11 & .309 & & & - & & & \\
\hline & 4 & $51-60$ & 20 & 3.15 & .489 & & & & - & & \\
\hline & 5 & $>60$ & 8 & 3.12 & .354 & & & & & - & \\
\hline
\end{tabular}

\section{E. Correlation Analysis}

The study did the correlation analysis among the dimensions of career burnout and those of organizational commitment and turnover intention. The results suggested that two dimensions of career turnout as emotional exhaustion and cynicism and three dimensions of organizational commitment as affective commitment, ideal commitment and economic commitment had a significant negative correlation. We did further correlation research of each variable and didn't find anomalies in mean and SD. In terms of the variable correlation, career burnout had a significant negative effect on organizational commitment $(\mathrm{P}<0.01)$ and a significant positive effect on turnover intention $(\mathrm{P}<0.01)$. And organizational commitment and turnover intention correlated significantly negatively $(\mathrm{P}<0.01)$. 
TABLE III. CORRELATION ANALYSIS OF VARIABLES

\begin{tabular}{|l|c|c|c|c|c|c|c|c|c|c|}
\hline & mean & SD & $\mathbf{1}$ & $\mathbf{2}$ & $\mathbf{3}$ & $\mathbf{4}$ & $\mathbf{5}$ & $\mathbf{6}$ & $\mathbf{7}$ & $\mathbf{8}$ \\
\hline 1.Occupation & 1.51 & .501 & & & & & & & & \\
\hline 2.Age & 2.13 & .990 & -.013 & & & & & & & \\
\hline 3.Gender & 1.64 & .482 & $.307 * *$ & -.028 & & & & & & \\
\hline 4.Education & 2.14 & .878 & $-.158 * *$ & $.282 * *$ & $-.125^{*}$ & & & & & \\
\hline 5.Job Title & $\mathrm{s} 2.56$ & .841 & $-.120^{*}$ & $.128 *$ & .030 & $.370 * *$ & & & & \\
\hline 6.Martial Status & 1.77 & .582 & -.063 & $.314 * *$ & .004 & $.160 * *$ & $.168^{* *}$ & & & \\
\hline 7.Career Burnout & 3.20 & .434 & .036 & $-.149 * *$ & .108 & -.084 & -.098 & $-.115^{*}$ & & \\
\hline 8.Organizational Commitment & 2.13 & .757 & .020 & .108 & -.006 & $.227 * *$ & $.214^{* *}$ & .005 & $-.221 * *$ & \\
\hline 9.Turnoer Intention & 2.34 & .601 & -.026 & $-.128 *$ & -.013 & $-.167 * *$ & $-.164 * *$ & -.035 & $.236^{* *}$ & $-.462 * *$ \\
\hline
\end{tabular}

a. ${ }^{* *}$. Corre lation is significant at the 0.01 level (2-tailed)

b. *. Correlation is significant at the 0.05 level (2-tailed)

\section{F. Regression Analysis}

“Table 4" showed the regression analysis result of organizational commitment and turnover intention. The VIF of model 1-6 are all below the critical value 10 , and $\mathrm{D}-\mathrm{W}$ is significant at the level of 0.05 , indicating that the model does not have the serious problem of collinearity and the results are acceptable. From the models in the table 4, career burnout had a significant negative effect on organizational commitment ( $\beta=-0.199, \quad \mathrm{p}<0.001)$ and a significant positive effect on turnover intention $(\beta=0.217, \quad \mathrm{p}<0.001)$. These results support $\mathrm{H} 1$ and $\mathrm{H} 2$.

TABLE IV. REGRESSION ANALYSIS OF CAREER BURNOUT AND TURNOVER INTENTION

\begin{tabular}{|l|l|l|l|l|}
\hline & \multicolumn{2}{|c}{ Organizational commitment } & \multicolumn{2}{c|}{ Turnover intention } \\
\hline & \multicolumn{1}{|c|}{ Model 1 } & \multicolumn{1}{c|}{ Model 2 } & \multicolumn{1}{c|}{ Model 5 } & Model 6 \\
\hline Constant & 1.362 & 2.258 & 2.912 & 1.903 \\
\hline Control variable & & & & \\
\hline Occupation & .065 & .062 & -.055 & -.052 \\
\hline Age & .061 & .038 & -.091 & -.066 \\
\hline Gender & -.008 & .014 & -.009 & -.033 \\
\hline Education & $.169 * *$ & $.169 * *$ & -.111 & -.110 \\
\hline Job title & $.162 * *$ & $.147 * *$ & $-.123^{*}$ & -.106 \\
\hline Marital status & -.064 & -.077 & .029 & .043 \\
\hline Independent variable & & & & \\
\hline Career burnout & & $-0.199 * * *$ & & $.217 * * *$ \\
\hline R2 & 0.081 & 0.119 & 0.051 & 0.096 \\
\hline Adjusted R2 & 0.063 & 0.099 & 0.033 & 0.076 \\
\hline F & 4.675 & 6.127 & 2.849 & 4.828 \\
\hline$\Delta$ R2 & 0.081 & 0.038 & 0.051 & 0.045 \\
\hline F & 4.675 & 13.725 & 2.849 & 15.905 \\
\hline
\end{tabular}

\section{CONCLUSION AND DISCUSSION}

\section{A. Discussion}

1) The career burnout of the medical staff consists of emotional exhaustion, cynicism and low personal accomplishment, among which the last is the most important. In the exploration of characteristics influential factors, the study found age has a significant effect on the variables while gender, marital status, education, job category and job title do not.

2) The emotional exhaustion and cynicism of career burnout have a significant negative effect on the emotional commitment, ideal commitment, normative commitment and economic commitment. As a whole, career burnout and organizational commitment is highly negatively correlated. Because of the high work pressure and complicated doctor- patient relationship, doctors can easily develop career burnout, which will certainly lead to the decrease in organizational identity and ineffectiveness of the job. The results support $\mathrm{H} 1$.

3) Career burnout is significantly negatively correlated with turnout intension $(\mathrm{P}<0.01)$. High career burnout level can lead to high turnout intension. Career burnout consists of emotional exhaustion, cynicism and low personal accomplishment. When the medical staff lack enthusiasm in the organization, working half-heartedly, and have a negative evaluation of their own, they will find themselves bum and ineffective, and are often prone to turn out. The results support $\mathrm{H} 2$. 


\section{B. Management Implications}

1) Medical staff should understand career burnout and themselves correctly. They should fully understand their strengths and weaknesses, define their physiological and psychological changes, look for ways to release themselves, learn to improve self-regulation and rationally divine boundaries of work and life and stick to the right career beliefs and ideals.

2) Hospital management should focus on the match between medical staff and job, not only in the technical expertise, but also in personality traits. Giving them decision-making power, establishing a good organizational climate, improving the internal appraisal and compensation system, reducing in sense of unfairness, and actively health education are also helpful. Managers should also pay attention to the career development of medical staff and enhance the guiding role of master.

3) In terms of the social policy, hospitals should improve the material benefits of medical staff appropriately and increase their income, because of the high risk and pressure and high requirements of techniques. Improving relevant policies and regulations, enhancing the understanding of medical social groups, and eliminating "red packet" and other phenomena are also helpful to avoid medical disputes. Establishing a multi-level medical system is also helpful to reduce their pressure.

\section{Limitations and Directions for Future Research}

The limitations of the research are as follows: relatively simple sample source, less pluralistic sample-level, use of western scales in multi-national conditions.

Based on the insufficiency of the research and existing researches, we predict future research could be improved in following directions:

1) Enrich the sample. Due to the limitations of the sample, we need to enrich the sample source, increase staff investigation of other hospital staff in order to distribute the sample multi-levelly and fully reflect the actual working conditions of the hospital.

2) Explore the mechanism further. The study only focused on how characteristics effects career burnout and how career burnout effects organizational commitment and turnover intention. Future study could further explore the relationship between occupational characteristics and medical social and organizational factors and career burnout. The relationships among career burnout, organizational commitment and turnout intention in the research still need to be examined further. Besides, future research may also be more concerned about the impact mechanism of career burnout under the background of China's medical reform.

\section{REFERENCES}

[1] Freudenberger HJ. Staff burnout. Journal of Social Issues, 1974, 30: $159-165$.
[2] Shirom A. Job-related burnout: A review. In Quick J.C, Tetrick L.E. (Eds). Handbook of Occupational Health Psychology. DC: American Psychological Association, 2003:245-264

[3] Harden RM. Stress, pressure and burnout in teachers: Is the swan exhausted ? Medical Teacher, 1999, 21(3):245-247.

[4] Tang Hanying, Ma Hongyu et al. Research on the relationship betwee $\mathrm{n}$ family conflict and job burnout of clinical doctors [J]. Chinese Jour nal of clinical psychology, 2010,18 (2): 219- 222

[5] Wang Hui, Zhang Ning. Analysis of occupational burnout and related factors of [J]. Chinese Journal of clinical psychology, 2009,17 (1): 11 2- 114

[6] Swider BW, Zimmerman RD. Born to burnout: A meta-analytic path model of personality, job burnout, and work outcomes [J]. Journal of Vocational Behavior, 2010, 76(3): 487-506.

[7] Ling Wen Quan, Zhang Zhican, Fang Liluo. Model [J]. Journal of ma nagement science research Chinese employees' organizational commit ment, 2000,3 (2): 76-81. 